\title{
Plans Underway for MRS-Asia Formation
}

\author{
R. P. H. Chang Visits Asia on Behalf of Society
}

\section{Background}

In January of this year, a new MRS activity on International Relations was formed to foster communications between $M R S$ and the international community of materials scientists. $R$. P. H. Chang was appointed Chairman, International Relations by MRS President Elton N. Kaufmann. Chang, a member of the technical staff of ATET Bell Laboratories in Murray Hill, New Jersey, is an active member of MRS and has international contacts and maintains personal awareness of materials research endeavors around the globe.

In making the appointment, President Kaufmann stated, "Bob Chang's past participation in MRS activities and his enthusiastic espousal of greater worldwide communication among materials researchers makes him the right man for this role in the growth of our Society. Bob is a frequent traveler to Europe and Asia and is well known on three continents. He is also well acquainted with many research leaders throughout the world."

The creation of Chang's position, according to Kaufmann, recognizes $M R S^{\prime}$ s growing involvement and interest in European and Asian membership, and the manifest need for a single point of contact through which communication with MRS can be maintained.

The following article summarizes Chang's first trip to Asia as emissary for the Society. His discussions with research communities in Japan and China demonstrate a growing enthusiasm by the Asian materials profession for extending $M R S$-style meetings and programs in this area of the world.

The first meeting of the MRS-Asia Committee convened in April in Tokyo to formulate plans for development of MRS activities in this geographical region. R. P. H. (Bob) Chang, newly appointed Chairman, International Relations, participated in the meeting on behalf of the Society, during the first leg of his two-week trip to Asia to confer with materials research leaders regarding the role of MRS in Asian science.

Table I:

Attendees at the First MRS-Asia Committee Meeting

T. Tokuyama (Hitachi)

T. Takeishi (Toshiba)

H.-L. Hwang (Tsing Hwa University) S. Miyazaw (MIT)

S. Namba (Osaka University)

M. Doyama (University of Tokyo)

T. Sugano (University of Tokyo)

S. Somiya (Tokyo Institute of Technology)

I. Ohdomari (Waseda Univerity)

R. P. H. Chang (AT\&T Bell Laboratories)
The purpose of the recent Asia trip, according to Chang, was to "offer information, advice, and assistance on behalf of the Society to groups within Asia that had expressed interest in the Society."

Chang arrived in Japan on March 30 and attended the MRS-Asia Committee meeting in Tokyo on the following day. The gathering, which Chang helped to organize, was arranged to coincide with the meeting of the Japan Society of Applied Physics, which brought many of the MRS-Asia Committee participants to the city (see Table I).

At the meeting, MRS was introduced, its philosophy and purpose reviewed, and the operational details attendant to past meetings in both the United States and Europe were outlined. The committee also heard how the European MRS organization was nucleated and how its operations differ in detail but not in spirit from those that are carried out in the United States. Chang's basic message to the group was that "MRS members welcome the formation of new groups whose activities can be coordinated globally." Futhermore, he said, "The Society recognizes that its function-the furtherance of interdisciplinary materials research-does not require identical forms and formats throughout the world. MRS encourages each group to choose methods that best serve its needs."

The consensus of the participants at the Tokyo meeting was that detailed planning for the structure of MRS-Asia would be best set aside in favor of the more rewarding prospect of organizing an interdisciplinary gathering in Asia-first things first!

\section{International Meeting Discussed}

The remainder of the meeting then concentrated primarily on planning an MRS-Asia meeting that would be international in scope. The committee suggested that the IBMM (Ion Beam Modification of Materials) conference planned for Japan in 1988 might provide an ideal focus for an expanded program. The committee proposed that MRS

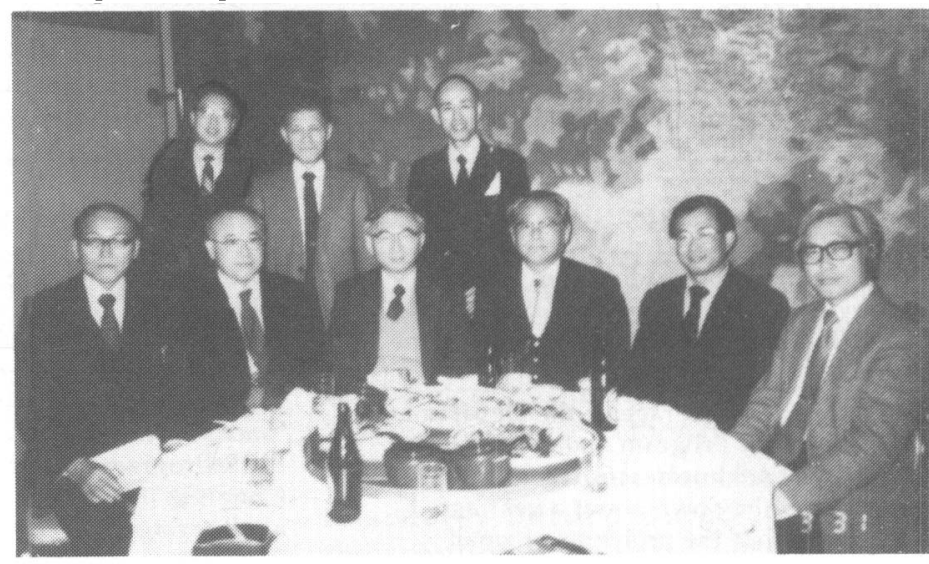

MRS-Asia Committee (left to right): M.Doyama, Bob Chang, T. Sugano, T. Takeishi, S. Somiya, T. Tokuyama, S. Namba, H.-L. Hwang and I. Ohdomari. 
(which has been an IBMM sponsor in recent years) and MRS-Europe cosponsor the expanded program and that Asian societies such as the Japan Society of Applied Physics, the Physical Society of Japan, and others also be invited to support the event as cosponsors. Two additional symposia of broad appeal were suggested, covering electronic materials and other advanced materials topics, which would be more clearly defined by the individual symposia committees.

Numerous follow-up meetings between Chang and individual members of the committee served to further refine and solidify the proposal, which was presented to and approved by the MRS Executive Committee at the Society's Spring Meeting in San Francisco.

\section{Week-Long Trip to China}

Following a week in Japan, Chang visited China where he was a guest at Fudan University in Shanghai. At Fudan, he met with scientists in the departments of Electrical Engineering, Physics, and Materials Science, as well as with the president of the university, Prof. Xie.

Again, Chang reviewed the history and philosophy of MRS and related the Society's interest in Asian participation. Chang reported that "response to the prospect of a meeting in Asia was very positive within the Shanghai group."

He also visited the Shanghai Institute of Metallurgy, a part of the Chinese Academy of Science. Prof. Zou, director of the institute, and various additional leaders within the institute expressed keen interest in the meeting, and indicated a strong desire to participate. On his visit to the

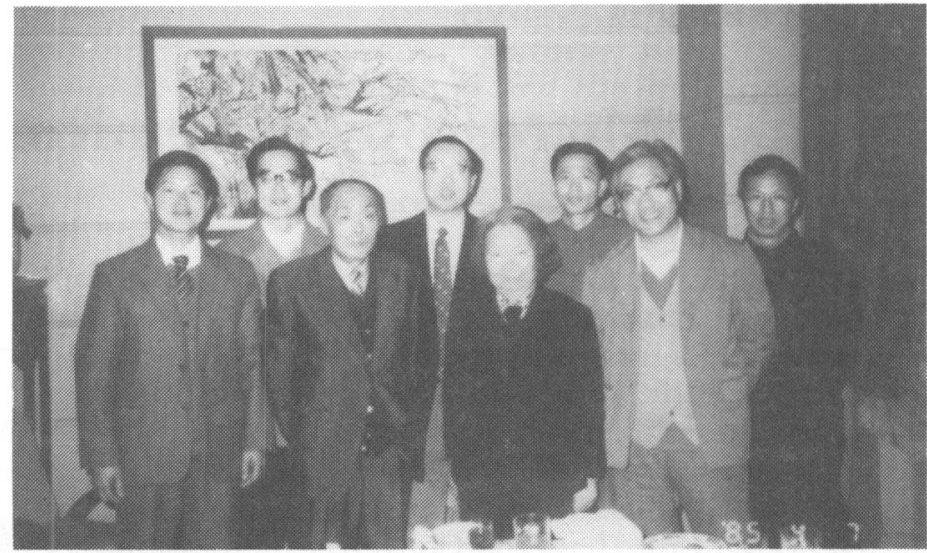

Bob Chang (fourth from left) meets with faculty of Fudan University, Prof. Xie, president of the university, is fifth from left.

Shanghai Institute of Ceramics, which conducts programs on electronic materials, hydrothermal crystal growth, and other advanced materials topics, he once again encountered enthusiasm for MRS and for the proposed Asian meeting, through the institute's deputy director, Prof. Wang.

In assessing his trip upon his return to the United States, Chang remarked that,"While the Asian nations do not lack for disciplinary societies, the people with whom I met were intrigued by the possibilities of an interdisciplinary gathering. I believe that the proposed international meeting will be successful and will serve as a model for future MRSstyle gatherings in Asia."

\title{
Attention MRS-Europe Members
}

\author{
If you attended the 1984 MRS-Europe Meeting in Strasbourg but were unable \\ to attend the 1985 Meeting held in May, your membership is expiring and this \\ is the last issue of the MRS BULLETIN you will receive.
}

\author{
Check your mail for a letter from the Secretariat of MRS-Europe to learn how \\ you can continue your involvement with MRS and stay in touch with \\ developments in materials through MRS BULLETIN.
}

